Meta

Journal des traducteurs

Translators' Journal

\title{
Literary History and Translation: An Indian View
}

\section{G. N. Devy}

Volume 42, numéro 2, juin 1997

Lexicologie et terminologie II (1) et Traduction et post-colonialisme en Inde

Translation and Postcolonialism: India (2)

URI : https://id.erudit.org/iderudit/002560ar

DOI : https://doi.org/10.7202/002560ar

Aller au sommaire du numéro

\section{Éditeur(s)}

Les Presses de l'Université de Montréal

ISSN

0026-0452 (imprimé)

1492-1421 (numérique)

Découvrir la revue

Citer cet article

Devy, G. N. (1997). Literary History and Translation: An Indian View. Meta, 42(2), 395-406. https://doi.org/10.7202/002560ar

\section{Résumé de l'article}

Un examen des relations entre les formes littéraires canoniques et non canoniques, entre le "moi" et "l'Autre" dans la littérature indienne permet de différencier la tradition occidentale- centrée sur un modèle littéraire dominant--, de la tradition indienne qui, elle, est diversifiée, multiforme. Cette tradition est ancrée dans un univers où multilinguisme et traduction, en étroite interaction, contribuent à créer une "conscience traductive". Dans cet univers où une pluralité de langues se trouvent simultanément mobilisées, la traduction joue un rôle fondamental, véritablement proligère. 


\title{
LITERARY HISTORY AND TRANSLATION: AN INDIAN VIEW
}

Bhasha Research and Publication Centre, Baroda, India

\begin{abstract}
Résumé
Un examen des relations entre les formes littéraires canoniques et non canoniques, entre le «moi» et «l' Autre» dans la littérature indienne permet de différencier la tradition occidentale - centrée sur un modèle littéraire dominant -, de la tradition indienne qui, elle, est diversifiée, multiforme. Cette tradition est ancrée dans un univers où multilinguisme et traduction, en étroite interaction, contribuent à créer une «conscience traductive». Dans cet univers où une pluralité de langues se trouvent simultanément mobilisées, la traduction joue un rôle fondamental, véritablement proligère.
\end{abstract}

\begin{abstract}
A discussion of the relations between canonized and non-canonized literary forms, between 'self' and 'other', within the Indian context, leads to a differenciation between the Western tradition of a single dominant literary tradition and the more diverse, and inclusive, parallel and multiple traditions of India. At the origin of such traditions, and holding them together long enough to permit cross fertilization, are acts of translation, merging sign systems and forming a community of 'transiating consciousness' where several languages are used simultaneously and are parts of a larger, continuous spectrum. Translation in such a multilingual context plays a fundamental role, transforming and revitalizing original texts.
\end{abstract}

Literary history has always treated literary translations as a branch of non-canonical or para-literature. In the Indian literary tradition, translation has had a place of crucial importance since most literary traditions in modern Indian languages originate in some pioneering work of translation. Therefore, in order to understand the significance of translation in Indian culture, it becomes necessary to discuss at some length the notions of "para" and "tradition", as well as the phenomenology of the self and the other. What follows is a modest attempt in that direction.

\section{PARA-LITERATURE}

"In every literary epoch there is," according to Russian Formalism, "not one but several literary schools. They exist in literature simultaneously, but one of them represents the canonized crest. The others are not canonized and exist obscurely..." Formalistic historiography allows for an element of arbitrariness in canon formation, which it describes by the expression "automatization-perceptibility". Once allowance is made for the mysterious arbitrariness in how some literary trends get to become the canonized crest and others exist obscurely, the creation, existence and decline of the non-canonized other trends becomes a foreclosed question. However, the question of obscure traditions, marginal styles and non-canonized texts is of utmost importance to literatures with multilingual historical contexts. The question has a great political urgency in societies that have experienced colonial domination and gender discrimination.

Let us try to conceptualize the other, obscure, suppressed or subcultural literary phenomena by using the epithet "para". This prefix has travelled from its Greek origin 
through Latin, and Middle French to Middle English, retaining most of its original sense, and it now means "by the side of, beside, alongside of, past and beyond." Para-literature would, therefore, include all such activites as are normally considered socially parallel, linguistically parasitical, psychologically paranoid and historically parenthetical. What is common to all forms of para-literature is that they are literature without interlocutors, a taboo as far as literary history is concerned.

Para-literature occupies the middle space between literature and non-literature. It is not literature, because it is not accepted in literary canons. It is also not non-literature, because it has the formal attributes of literature. Para-literature is, thus, the literature of the middle space.

The middle space is densely populated. It contains a bewildering range of forms of linguistic creativity, such as science and crime fiction, magazine stories, film and television scripts, street-plays, biographies, autobiographies, memoirs, travelogues, philosophic writings, religious discourses, popular and folk songs, folklore, proverbs, mantra, tantra and liturgical verses, lullabies, oral narratives, archaic literature, slang and dialect works, children's literature, performed poetry (as in mushairas ${ }^{2}$ ), pornography, graffitti, comics, advertisements, jokes, cartoons, translations and adaptations. Of course this is a random list of middle-space literary forms.

Middle-space literature can be differentiated from non-literature by virtue of its context, style and performance. In other words, middle-space literature is not without aesthetic form, unlike non-literature. All forms of middle-space literature involve a certain linguistic skill and aesthetic sensibility. They have their own distinctive discourses and conventions, standards of excellence and criteria of achievement. They all have their cultural uses. Any language would be much the poorer without these or similar forms of linguistic creativity.

When new literary traditions emerge, or branch off from an established literary tradition, the new literatures are initially treated as taboo/para-literatures. The history of literature in modern Indian languages tells us that in the initial period of development of these new traditions, the period of transition from Sanskrit to these new languages was seen as a gradual vulgarisation. A similar attitude was displayed in Europe towards the literatures and languages branching out of Latin in medieval Europe. In the early phases of English literary writing outside England and Scotland, in countries like Ireland, the United States and Australia, the British attitude to such literature was invariably patronizing. On the other hand, when a literary tradition acquires substance, the preceding literary trends or traditions lose their acquired status. Though it is true that all obsolete literature does not get relegated to the category of para-literature, literary history does keep agitating against literary obscolescence.

However, not all para-literature is a product of literary history's amnesia, nor is all of it the result of hesitation on the part of literary criticism to assimilate new modes of writing. Much of para-literature is downgraded to that status due to contemporary repressions guided by hierarchic stratification within a community. In most communities a lower "aesthetic" value is attached to literature produced by and for children and women in literary criticism and history controlled by the males and adults of those communities. Children and women form two major repressed segments of most communities. Their literary requirements, and aesthetic sensibilities are taken less seriously than they deserve. Para-literature therefore accurately reflects the patterns of social repression. In addition to these, there is one more conventional method of repression in India. The subcontinental and poly-linguistic country has always had a common mainstream literary tradition, whether in Sanskrit, Pali, Persian, Hindi or English. The regional literary traditions in India have to encounter the imperialism of the mainstream traditions. At present, this is the condition 
of about eighty-five tribal and minority languages, and literary forms in them. These are languages spoken by more than 100,000 speakers each but not listed as languages of administration in the Eighth Schedule of India's constitution. The literary aesthetics of these languages is never given even the minimum passing consideration in Indian literary discourse. Their situation is like that of literatures in Indian languages in relation to the contemporary world canon of literature. Para-literature is thus the literature of linguistic communities on the periphery of political orders.

The psychological desire to castrate one's adversary often takes linguistic expression. The linguistic creativity of politically subjugated sections is then made a victim of this desire by the dominating language groups. During the nineteenth century, European anthropologists turned perfectly normal literary activity in Africa into para-literature. Orientalism did the same for the Asian nations. Para-literature, in which it is a usual practice to include oral narratives and folk forms, is perceived to be closer to the region of the unconscious.

The primitive in society, the unconscious in the psyche, and the "para" in literature may have intrinsic attributes in a given period, but these are not absolute categories. Their attributes in a given period are gradually determined over a preceding long period through processes of repression. Therefore, what is civilized can come to be considered primitive, what belongs to accessible areas of consciousness can be relegated to the territory and terror of the unconscious, and what is literature can invite description as para-literature. Movements in the opposite directions too are possible. These movements are of crucial formative importance in the history of literature, both as system of totems and taboos, and as dynamic cultural practices.

Since there is essentially no difference between literature and para-literature, the boundaries between the two are not permanently sealed. There is a constant mutual exchange between the two. This exchange proceeds along certain established lines. To articulate the nature of this exchange should be one of the primary objectives of literary history. As in the history of language, so too in the history of literature, the trends and styles initially developed on the margins tend to gravitate towards the centre. Removed from the original context, sometimes the para styles change their intended performance in the changed literary context. Conventions of comic literature often originate in the not so comic dialects of the socially less-privileged classes. Conventions of the tragic, epic and canonical originate in the well-formed registers of the socially privileged classes. Once formulated, these languages and literatures become socially-usuable systems. Thus, the marginal (or, desi: regional) and the dominant (or, marga: mainstream) literary traditions keep alternating their positions. This continuous and inevitable mobility of literary conventions is what the term "evolution" of literature should rightly imply. Literature, as a social and cultural activity, is a continuous re-ordering of the total field of meaning available to a society through language, a continuous re-structuring of various levels of received language. Literature, in order to be socially meaningful, has to re-appropriate the sources of language so as to invest the language system with new possibilities of consciousness. Hence, the linguistic activity on the margins of a language community, the para-literary activity, has an important role to play in the literary enrichment of that language. For this reason it deserves attention by literary history.

It may be said that the distinction between literature and para-literature is not a distinction between two different fields, but a distinction within a single field, as the one between totems and taboos within a single cutlure, or as between the self and the non-self within a single field of consciousness. The political dispossession of linguistic and social margins is the root cause of the creation of the category. The relationship between literature and para-literature is closely comparable to that between the psychologically masculine, 
and the psychologically feminine other. It is a relationship in which the female other is seen as being closer to the unconscious, the primitive, the marginal, and yet indispensable. Ultimately, it is the need for this dialectics of self-cognition for literature that creates the category of para-literature.

If the dialectical relationship between the dominant trends and marginal trends is considered a process forming the backbone of the history of literature, it would still be necessary to specify the nature of this dialectics in a given culture, for it may vary from culture to culture. In other words, canon formation may be a common experience for all literatures in the world, but the processes through which canons are formed in a given literary culture are likely to be peculiar to that particular literary tradition. It is not enough for literary history to describe the canon; it is also necessary, and even more important, to explain the culture-specific processes of canon formation so as to make literature a sociallyintegrated sub-system of culture. Therefore, if the relationship between literature and para-literature is of vital importance to the self-cognition of literary canons, it would be essential for any perspicuous literary history to consider the nature of a society's narcissistic structure.

\section{SWA AND PARA: SELF AND THE OTHER}

It is at this stage that we have to introduce another term to help us conceptualize the narcissistic structure of Indian society, as understood in Indian traditions. The term we can use is para, which is accepted by a large majority of modern Indian languages as the term for "other". The original Sanskrit term, replete with meanings, indicates: "distant, further, enemy, afterwards, beyond, other, far off, etc." Its superlative form, param, however, moves onto a more idealistic plane by generating sacred terms such as parameswar, parabrahman, terms related to the discourse of the other world. The term is shared by Dravidian languages too, with revealing deviations. Tamil uses parai as the term for drums played by outcaste drummers of the paraiyan community, which, incidentally, is also the origin of a similar English term, "pariah". One is not sure if the Greek para and the Sanskrit para have a forgotten common source, but it is possible to deduce from the linguistic evidence we have that in all languages in which the Greek and the Sanskrit term para has been assimilated, it is used to indicate "otherness" as a psychological phenomenon as well as a spatial term, as if the psychological space is revealed through this term as a geographical metaphor. Thus the modern English has "parish" and "parochial" indicating restricted psychological and geographical spaces. In Indian languages the term paradesh is used to indicate foreign or alien land. Such peculiar use of the term for describing space as well as otherness, indicating the unarticulated wisdom inherent in human languages, is properly theorized in the following formulation by Jacques Lacan:

The notion of the role of spatial symmetry in man's narcissistic structure is essential in the establishment of the basis of a psychological analysis of space [...] Let us consider that animal psychology has shown us that the individual's relation to a particular spatial field is, in certain species, mapped socially, in a way that raises it to the category of subjective membership. I would say that it is the subjective possibility of the mirror projection of such a field into the field of the other that gives human space its originally 'geometric' structure, a structure that I would be happy to call kaleidoscopic [...] Such, at least, is the space in which the imagery of the ego develops, and which rejoins the objective space of reality. ${ }^{3}$

Indian epistemology too admits the kaleidoscopic structure within the ego-space. But the kaleidoscoping it visualizes is not between the field of the self and the field of the nonself. It is rather between the field of the self and the field of the greater-self. It is a theologybound epistemology. The Katha Upanishad is eloquent on this issue: 
The tree of eternity has its roots in heaven above and its branches reach down to earth. It is Brahman [...] Brahman is seen in a pure soul as in a mirror clear, and also in the Creator's heaven as clear as light, but in the land of shades as reflections in trembling water. When the wise man knows that the material senses come not from the Spirit, and their waking and sleeping belong to their own nature, then he grieves no more. Beyond the senses is the Spirit of man, and beyond this is the Spirit of the universe, and evolver of all. And beyond is Purusha, all pervading, beyond definitions. ${ }^{4}$

Here too, as in Lacan, the key terms are mirror and reflection, which complete the grand hoop of human consciousness by inductive leaps. But the mapping of the narcissistic structure is different. Indian texts, whether emerging from the Vedas, the Upanishads, or secular literature, see the self and the non-self as reflections of Purusha, the greater-self, as mere passing images of a reality beyond human perception. In that sense the dichotomy between the self and non-self has not been conceptualized in radical terms. Buddhist psychology too did not visualize any such opposition between the self and the non-self. In fact, the entire spectrum of human existence is seen in Indian thought in terms of a complex continuum. To introduce concepts of polarities in it is considered by Indian thought as tantamount to a profoundly ignorant act of consciousness. How can one reconcile this concept of the ego-space with the rational experience of the senses, which form the physical basis for the recognition of the non-self? Traditional Indian epistemology circumvents this difficulty by introducing a taxonomy of knowledge. Indian tradition divided knowledge into false knowledge, avidya, and authentic knowledge, vidya. The two are not radically different, but they can be recognized as such in terms of a polarity in the spectrum of knowledge. Avidya is the knowledge flowing from the senses to the soul. Vidya, on the contrary, is the knowledge flowing from the soul to the senses. The knower of vidya is a guru, a spiritual guide. These categories were neatly separated from those related to systematized perception of material phenomena, for which the terms gnana and vignana (approximately corresponding to modern humanities and science, respectively) were employed. The knower of the latter was acarya, a teacher, a scholar. An experience of para, the foreign or alien, thus brings in to play the knowledge of the other, which, when it is guided by vidya (spiritual knowledge) obscures the duality between the self and the non-self, leading to a recognition of the self within the non-self. Sudhir Kakar, who has presented highly-engaging theses on Indian psychoanalysis, comments at length on the sense of the self in Hindu tradition in his study The Inner World. His observations as a professional scholar of psychology would be of immense use to us in defining the priorities of Indian literary history. Discussing the concepts of $I, E g o$ and Self, he writes:

The distinctions between vidya and avidya - true and false consciousness - between reality and maya, illustrate a fundamental difference between Hindu and Western world images, as well as a discrepancy in the modes of thought and apperception, which even the bestintentioned movements of cultural ecumenism cannot hope to bridge satisfactorily. The maintenance of ego boundaries, between 'inside' and 'outside', and between 'I' and 'others', and the sensory experiences and social relations based on these separations, is the stuff of reality in Western thought and yet maya to the Hindus. The optimal discrimination of this reality of separateness, expressed in terms of heightened ego functions such as reality sense, reality testing and adaptation to reality, is the stated goal of most Western psychotherapies, but of paltry importance in the Hindu ways of liberation. A good reality sense, according to psycho-analysis, shows itself in the absence of a conscious feeling of the self or the various selves. This, however, is precisely the situation which the Hindu ways of liberation would seek to reverse. And if in the course of development the child learns to differentiate between himself and what is not a part of him, between 'me' and 'not-me' - a process in which the individual's sense of space, time, causality and individuality are formed, and ego boundaries are constituted, then in a certain sense the Hindu ways of liberation [...] seek to undo this process of ego development. 5 
If, as modern psychoanalysis tells us, the tendency of the dominant Indian psychological type is towards establishing the non-duality of self and non-self in the narcissistic field, the tendency in the altruistic field must, therefore, be that of allowing a free interplay between the central and para cultural elements.

It would, however, be inaccurate to think that the Aryan epistemology of the selfother relationship remained unchanged in the long history of India. Hinduism has been an amorphous mass of ideas and practices, within which an amazing variety of dissenting viewpoints emerged and eventually merged. Besides, for about a thousand years India has produced a powerful and complex tradition of Indian Islam, and for two centuries created hybrid cultural practices out of the encounter with the modern West. Yet, the amazing capacity to assimilate alien cultural, linguistic, and literary elements is a unique and essential feature of Indian history. Though the Western countries too have been exposed to a very large number of alien cultures during the last two hundred years, their assimilation of alien cultural traits has been relatively restricted, corresponding to their relationship of otherness with the foreign cultures.

It is of course not true that metaphysics of non-duality between the self and the non-self did not create social stratification in India. All the plethora of evidence in Indian history goes directly against such an assumption. No other society in the world is, and was, perhaps, more fragmented, stratified and torn with strife than Indian society. It is divided linguistically, regionally, in terms of caste, income, faith, and profession. What is true, perhaps, is that the tendency towards dissension is counterbalanced by a political and social organization based on consensus. It is for this reason that a careful study of the exchanges between literature and para-literature becomes all the more vital to a proper understanding of India's literary past, and thereby the literary present.

\section{TRADITION AND TRANSACTION}

European literary historiography uses the paradigm of a single dominant literary tradition. There is very little debate about the central canon of British literature. Occasional debates about particular preferences of styles and periods do take place, as the one created by T. S. Eliot's preference for the Metaphysicals over the Romantics; but the overall range of the canon has never been in doubt. At no stage in the traditions of English literary criticism was there allowance made for a non-British writer to be included in the British canon, even when some very good works were produced in the language of the British Isles outside, on other continents. On the other hand, in India, a writer with Greek ancestry as Asvaghosa, with Irish nationality as Nivedita, with Caribbean background as Naipaul, with Arabic training as Ibn Battuta, have been accepted as Indian writers. Languages such as Persian, Arabic, English, French and Portuguese have been accepted in India as languages of Indian literature. The English canon has never thought of any translation as a great work of literature, the emphasis of Anglo-poetics being on the original (though perhaps the aesthetically most intricate work in English is the King James version of the Bible, a translation). In India some of the most respected literary classics have originated in attempts to translate: the Jnaneswari in Marathi, Kamban's Ramayana in Kannada, Tulsi's Ramayana in Hindi, Tagore's Gitanjali in English are some examples. Again, Indian literature has in it the peculiar phenomenon of bilingual writers. The number of bilingual writers in India is so large, and the longevity of this practice so substantial, that bilingual literature is more a norm than an exception in India. Considering these major differences in literary practices in India and Western countries, it is obvious that the concept of a single dominant literary tradition, a single and fairly welldefined literary canon and historical criticism couched in a unidirectional philology will not prove adequate to interpret the literary history of India. 
The particular problem for literary historiography can get a useful lead from developments in general historiography in India in recent years. In this respect, specifically useful is Ramila Thapar's important essay on tradition in Cultural Transaction and Early India: Tradition and Patronage. ${ }^{6}$ In this essay Thapar discusses the Indian concept of tradition, and more particularly the historical reconstruction of tradition. Through several convincing examples, she makes it clear that at any given time there might be a normative code of tradition, but at the same time there exist numerous deviations from the norm. It is therefore possible, as Thapar argues, to project a variety of traditions as dominant in Indian history and culture, none of which are more or less authentic that the rest. One of the striking examples she selects to put her view across is that of the Mahabharata. The story of Shakuntala used by Kalidasa existed in the Mahabharata previous to his rendering. The two versions have different philosophic and ideological orientations. After Kalidasa's use of the story, the two versions co-existed in Indian culture. Thapar asks: which of the two is authentic? Her answer is that authenticity of tradition arises out of subjective reading by historians:

For such a diverse community to create a uniform cultural tradition for itself can become an exercise in juggling with history. Traditions are not self-created: they are consciously chosen, and the choice from the past is enormous [...] If we are to understand the role of religion in the Indian society of earlier times we may have to move away from the paradigm of Hinduism and the other religions in India as projected in the colonial period [...] Complex societies have competing value systems and attempts are made by the more established to delete ideologies of protest or of divergent values...7

What is true of the national history of India is also, and far more pertinently, true of its literary history, given the multilingual literary context. Western historiography of literature is based on literary histories which do not have traditions fragmented in terms of multiple parallel traditions. The term 'parallel' can be applied to popular or folk traditions in European contexts. In India, the parallel traditions are really alternative traditions rather than 'lower' traditions. This point can be made clearer through some examples.

When Panini wrote his grammar in prechristian centuries, he spoke of two discourses of Sanskrit, one used by the common people and another that was grammatically correct. When Bharata composed his treatise on drama, he spoke of two types of theatre, one catering to the public and the other based on dramatic conventions. Both Panini and Bharata speak about the popular and the doctrinaire as insiders, not in terms of the self and the other. Dandin, a seventh century Sanskrit theoretician, describes several competing literary styles from different regions of India. They were all styles of Sanskrit poetry; in describing these, Dandin does not arrange them in an aesthetic or sociological hierarchy. In the eleventh century, Rajasekhara could write plays in Maharashtri as well as Sanskrit. Jayadeva, in the twelfth century, wrote poetry in Bengali as well as Sanskrit. Hemacandra, in the thirteenth century, wrote in Gujurati and Sanskrit. Namadeva wrote poems in Hindi and Punjabi too, in addition to writing in Marathi. Thyagaraja of Telugu had no hesitation in learning diction and metre of Gujarati poetry. Eknath prepared a scholarly edition of Inaneswara's Bhavarthadipika, using the written medium, and 'published' most of his own poems using the oral medium of singing. There are innumerable writers who write in Urdu and Hindi, Hindi and Punjabi, Oriya and Bangla, Gujarati and Marathi, English and some Indian language. None of them shows signs of any unusual anxiety about being torn or split between traditions. An average Indian reader, if he is reasonably well educated, reads works in his own language, in one or two other Indian languages, in English translation from other languages; and yet does not feel anxiety or guilt for the loss of his linguistic, literary or cultural identity. The Indian tradition has given to every sensitive Indian the capacity to internalize a multiplicity of traditions. In India, the folk traditions 
can be as erudite as the dominant lexical traditions; and apparently outmoded styles and diction can find unexpected revivals. Thus it would be improper to distribute the tradition either in clearly demarcated periods, or according to clearly demarcated class origins of literature. It would be inappropriate even to speak of literary tradition in terms of a tradition of texts in a single given language. A better approach would be to think of the literary history of India in terms of a constant exclusion of para-literatures from the cultural centers and a constant assimilation of para literatures into the centers of culture, and a complex pattern of conflict and collaboration of many minor traditions.

The idea of a pure state of authentic existence at the point of origin is not appropriate to view Indian literary history; probably it is not appropriate to view any literary history at all, except that of literature in proto-Indo-European, if it existed at all, for at that point of history we have with us nothing but a sense of mystery and myth. So far, Western literary historiography has not come to terms with the basic fact about literary history, that all traditions of literature originate in the act of translation. An act of translation holds two or sometimes more different traditions momentarily together for cross fertilization, and in that sense all translations are sahitya (literature).

\section{TRANSLATION AS ORIGIN}

"Translation is the wandering existence in a perpetual exile," says J. Hillis Miller. ${ }^{8}$ This statement obviously alludes to the Christian myth of the Fall, exile and wandering. In western metaphysics translation is an exile, a fall from the origin; and the mythical Exile is a metaphoric translation, a post-Babel crisis. Given this metaphysical precondition of western aesthetics, it is not surprising that literary translations are not accorded the same status as original works. Western literary criticism provides for the guilt of translations for coming into being after the original; the temporal subsequentiality is held as a proof of diminution of their literary authenticity. The strong sense of being an individual, given to Western individuals through systematic philosophy and the logic of social history, makes them view translation as an intrusion (a sometimes pleasurable intrusion) of "the other". This intrusion is desirable to the extent that it helps define one's own identity; but not beyond that point. It is of course natural for monolingual European cultures to be acutely conscious of the act of translation. The philosophy of individualism and the metaphysics of guilt, however, render European literary historiography incapable of grasping origins of literary traditions.

One of the most revolutionary events in the history of English style was the authorized translated version of the Bible. It was also the literary expression of Protestant Christianity. The recovery of the original spirit of Christianity was thus sought by Protestant England through an act of translation. It is well known that Chaucer was translating the style of Boccacio into English when he created his Canterbury Tales. When Dryden and Pope wanted to recover a sense of order, they used the tool of translation. Similar attempts were made in other European languages such as German and French.

During the last two centuries the role of translation in communicating literary movements across linguistic borders has become very important. The tradition that has given us writers like Shaw, Yeats, Joyce, Beckett, and Heaney in a single country - the tradition of Anglo-Irish literature - branched out of the practice of translating Irish works into English initiated by Macpherson towards the end of the eighteenth century. The body of literature called Indian-English Literature too has gathered its conventions of writing from the Indological activity of translation during the late eighteenth century and the nineteenth century. Many of the Anglo-Irish and Indian-English writers have been able translators themselves. Similarly, the settler colonies such as Australia, Canada, and New Zealand have impressive modern traditions of literature, which have resulted from 
the "translation" of the settlers from their homeland to alien locations. Post-colonial writing in the former Spanish colonies in South America, in the former colonies in Africa, and in other parts of the world has experienced the importance of translation as one of the crucial conditions for creativity. Origins of literary movements and literary traditions inhabit various acts of translations.

Considering the fact that most literary traditions originate in translation, and gain substance through repeated acts of translation, it would be useful for a theory of literary history if a supporting theory of literary translation were available. However, since translations are popularly perceived as unoriginal, not much thought has been devoted to the aesthetics of translation. Most of the primary issues too have not been settled in relation to translation: issues related to the "form" and "meaning" of translation. No critic has taken any well-defined positions about the exact placement of translations in literary history. Do they belong to the history of target languages, or do they belong to the history of source languages? Or do they form an independent tradition all by themselves? This ontological uncertainty which haunts translations has rendered translation studies a haphazard activity which devotes too much energy to the discussion of problems of the original meaning in the altered structure.

Unfortunately for translation, the various developments about the interdependence between meaning and structure in the field of linguistics have been based on monolingual data and situations. Even the sophisticated and revolutionary theoretical formulations proposed by structural linguistics are not sufficiently adequate to unravel the intricacies of translation activity.

Roman Jakobson ${ }^{9}$ is an important name in the history of structural linguistics. In his essay on the linguistics of translation he proposes a three-fold classification of translations: a) those from one verbal order to another verbal order within the same language system; b) those from one language system to another language system; c) those from a verbal order to another system of signs. As he considers, theoretically, complete semantic equivalence as the final objective of a translation act - which is not possible - he asserts that poetry is untranslatable. He maintains that only "creative translation" is possible. This view finds further support in Formalistic poetics, which considers every act of creation as a completely unique event. It is, however, necessary to recognize that synonymy within one language system cannot be conceptually identical with synonymy between two different languages. Historical linguistics has some useful premises in this regard. In order to explain linguistic change, historical linguistics employs the concept of semantic differentiation as well as that of phonetic glides. While the linguistic changes within a single language occur more predominantly due to semantic differentiation, they also show marked phonetic glides. However, the degree of such glides is more pronounced when a new language comes into existence. In other words, linguistic changes within a single language are predominantly semantic in nature, whereas the linguistic differences between two closely related languages are predominantly phonetic. Technically speaking, then, if synonymy within one language is a near impossibility, it is not so when we consider two related languages together.

Structural linguistics considers language a system of signs, arbitrarily developed, that tries to cover the entire range of significance available to the culture of that language. The signs do not mean anything by or in themselves, they acquire significance by virtue of their relation to the entire system to which they belong. This theory naturally looks offensively at translation, which is an attempt to rescue / abstract significance from one system of signs and to wed it with another such system. But language is an open system. It keeps admitting new signs as well as new significance in its fold. It is also open in the socio-linguistics sense that it allows an individual speaker or writer to use as much of it as 
he can or likes to do. If this is the case, then how "open" is a particular system of verbal signs when a bilingual user, such as a translator, rends it open? Assuming that, for an individual, language resides within his consciousness, we can ask whether the two systems within his consciousness can be shown to be materially different, whether they retain their individual identities within the sphere of his consciousness? Or do such systems become a single open and extended system? If translation is defined as some kind of communication of significance, and if we accept the structuralist principle that communication becomes possible because of the nature of signs and their entire system, it follows that translation is a merger of sign systems. Such a merger is possible because systems of signs are open and vulnerable. The translating consciousness exploits the potential openness of language systems; and as it shifts significance from a given verbal form to a corresponding but different verbal form it also brings closer the materially different sign systems. If we take a lead from phenomenology and conceptualize a whole community of "translating consciousness", it should be possible to develop a theory of interlingual synonymy as well as a more perceptive literary historiography.

The concept of "translating consciousness", and of communities of people possessing it, are not mere notions. In most third-world countries, where a dominating colonial language has acquired a privileged place, such communities do exist. In India several languages are simultaneously used by language communities as if these languages formed a continuous spectrum of signs of significance. The use of two or more different languages in translation activity cannot be understood properly through studies of foreign language acquisition. Such theories work round the premise that there inevitably is a chronological gap, an order or a priority scale in language-learning situations. The field is stratified in terms of value-based indicators L1 and L2, though in reality language-learning activity may seem very natural in a country like India. In Chomsky's linguistics the concept of semantic universals plays an important role. However, his level of abstraction marks the farthest limits to which the monolingual Saussurean linguistic materialism can be stretched. In actual practice, even in Europe, the translating consciousness treats the source language and the target language as parts of a larger and continuous spectrum of various intersecting systems of verbal signs.

Owing to the structuralist unwillingness to acknowledge the existence of any nonsystemic or extra-systemic core of significance, the concept of synonymy in the West has remained inadequate to explain translation activity. And in the absence of a linguistic theory based on a multilingual perspective or on translation practice, translation studies in the West overstate the validity of the concept of synonymy.

J. C. Catford presents a comprehensive theoretical formulation about the linguistics of translation in his work A Linguistic Theory of Translation (1964), in which he seeks to isolate various linguistic levels of translation. His basic premise is that since translation is a linguistic act any theory of translation must emerge from linguistics:

Translation is an operation performed on languages: a process of substituting a text in one language for a text in another. Clearly, then, any theory of translation must draw upon a theory of language - a general linguistic theory. ${ }^{10}$

The privileged discourse of general linguistics today is closely interlinked with developments in anthropology, particularly after Durkheim and Levi-Strauss. As noted previously, colonial Europe had distributed various fields of humanistic knowledge into a three-fold hierarchy: comparative studies for Europe, orientalism for the Orient, and anthropology for the rest of the world. In its various phases of development modern western linguistics has connections with all of these. After the discovery of Sanskrit by Sir William Jones, historical linguistics in Europe depended heavily on Orientalism. For a 
long time afterwards linguistics followed the path of comparative philology. And after Saussure and Levi-Strauss, linguistics started treating language with an anthropological curiosity. When linguistics branched off to its monolingual structuralist path, comparative literature still persisted in its faith in the translatability of literary texts.

Comparative literature implies that between two related languages there are areas of significance that are shared just as there may be areas of significance that can never be shared. Translation can be seen as an attempt to bring a given language system in its entirety as close as possible to the areas of significance that it shares with another given language or languages. All translations operate within this shared area of significance. Such a notion may help us distinguish synonymy within one language and the shared significance between two related languages.

The translation problem is not just a linguistic problem. It is an aesthetic and ideological problem with important bearing on the question of literary history. Literary translation is not just a replication of a text in another verbal system of signs; it is a replication of an ordered sub-system of signs within a related language. Translation is not a transposition of significance or signs. After the act of translation is over, the original work still remains in its original position. Translation is rather an attempted revitalization of the original in another verbal and temporal space. Like literary texts that continue to belong to their original periods and styles and also continue to exist through successive chronological periods, translation at once approximates the original and transcends it. The problems in translation studies are, therefore, very much like those in literary history. They are the problems or relationship between origins and subsequentiality. And as in translation studies, so too in literary history the problem of origin has not been tackled satisfactorily. The point that needs to be made is that probably the question of the origins of literary traditions will have to be viewed differently by literary communities with "translating consciousness". The fact that Indian literary communities do possess this translating consciousness can be brought home effectively by reminding ourselves that the very foundation of modern Indian literatures is laid through acts of translation, whether by Jayadeva, Hemcandra, or Michael Madhusudan Dutta, H. N. Apte, or Bankim Chandra Chatterjee.

We began our discussion in this section by alluding to the Christian metaphysics that conditions the reception of translation in the Western world. Let us allude to Indian metaphysics in conclusion. Indian metaphysics believes in an unhindered migration of the soul from one body to another. Repeated births is the very substance of the fate of all animate creations. When the soul passes from one body to another, it does not lose any of its essential significance. Indian philosophies of the relationship between form and essence, structure and significance are guided by this metaphysics. The soul, significance, is not subject to the laws of temporality; and, therefore, significance, even literary significance, is ahistorical in the Indian view. Elements of plot, stories, characters, can be used again and again by a new generation of writers, because Indian literary theory does not lay undue emphasis on originality. If originality were made a criterion of literary excellence, a majority of Indian classics would fail the test. The true test is the writer's capacity to transform, to translate, to restate, to revitalize the original. And in that sense Indian literary traditions are essentially traditions of translation. 


\section{Notes}

1. Shklovskii quoted in M. M. Bakhtin and P. N. Medvedev, The Formal Method in Literary Scholarship, trans. Albert J. Wehrle, Baltimore, The Johns Hopkins University Press, 1978, p. 160.

2. "A social gathering in the evening, often taking the form of a contest, at which Urdu poets recite their poems", Oxford Advanced Learner's Dictionary of Current English, Fifth edition, with a special supplement of Indian English, Jonathan Crowther (Ed.), Delhi, Oxford University Press, 1996.

3. Jacques Lacan, Ecrits, trans. Alan Sheridan, New York, Norton, 1977, p. 27.

4. The Upanishads, trans. Juan Mascaro, Penguin Classics, Harmondsworth, Penguin, 1965, p. 65.

5. Sudhir Kakar, The Inner World, Delhi, Oxford University Press, 1978, pp. 20-21.

6. Delhi, Oxford University Press, 1st Ed. 1987, 1994.

7. Ibid, p. 23 .

8. In a lecture delivered at the University of Bologna, October 1988.

9. "On Linguistic Aspects of Translation", in On Translation, R. A. Brower (Ed.), Harvard University Press, 1959, pp. 232-239.

10. J. C. Catford, A Linguistic Theory of Translation, London, Oxford University Press, 1965, p. vii. 